\title{
Potential Significance of Circular RNA in Human Placental Tissue for Patients with Preeclampsia
}

\author{
Yating Qianª Yuanqing Lu ${ }^{a}$ Can Rui ${ }^{a}$ Yujia Qian ${ }^{a}$ Manhong Cai ${ }^{a}$ Ruizhe Jiaa \\ aDepartment of Obstetrics, Nanjing Medical University Affiliated Nanjing Maternal and Child Health \\ Hospital, Nanjing, ${ }^{b}$ Fourth Clinical Medicine College, Nanjing Medical University, Nanjing, China
}

Key Words

CircRNAs • Preeclampsia • CircRNA microarray • MicroRNA sponge

\begin{abstract}
Aims: This study aimed to identify the different expression of circular RNAs (circRNAs) in the placental tissues of pregnant women with preeclampsia (PE) and to provide a new avenue of research regarding the pathological mechanisms of PE. Methods: In this study, we collected 40 placental tissues from PE patients and 35 placental tissues from gestational age-matched patients who gave premature birth. Arraystar circRNA Microarray Technology (KANGCHEN, Shanghai, China) was used to analyze the differential expression of circRNAs. According to the basic content of circRNAs in the two groups and their fold changes and due to the practicability of the designed divergent primers of each candidate circRNA, we selected three up-regulated circRNAs, hsa_circRNA_100782, hsa_circRNA_102682 and hsa_circRNA_104820, to validate the data. Real-time quantitative reverse transcriptase-polymerase chain reaction (qRT-PCR) was utilized to estimate the Ct values in both groups. We further evaluated the differences with a paired t-test and a receiver operating characteristic (ROC) curve. Results: Many circRNAs were found to be differentially expressed in PE placental tissues versus their controls; of these, 143 circRNAs were up-regulated and 158 were down-regulated. The expression levels of hsa_circRNA_100782 ( $p<0.05)$, hsa_circRNA_102682 $(p<0.05)$, and hsa_ circRNA_104820 ( $p<0.0001)$ were validated as significantly up-regulated in the experimental group compared with the controls. Finally, we performed a literature comparison to forecast the possible mechanisms of circRNA function during PE. Conclusion: circRNA expression significantly differed in placental PE tissues compared with controls. According to the circRNA microarray results and the existing papers, circRNAs may contribute to the pathogenesis of PE by acting as miRNA sponges; this possibility requires additional investigation in future studies.
\end{abstract}




\section{Cellular Physiology Cell Physiol Biochem 2016;39:1380-1390 \begin{tabular}{l|l} 
DOI: 10.1159/000447842 & O 2016 The Author(s). Published by S. Karger AG, Basel \\
www.karger.com/cpb
\end{tabular} \\ Qian et al.: Expression Difference of Placental circRNAs in Preeclampsia}

\section{Introduction}

Preeclampsia (PE), a specific complication of pregnancy, mainly causes injuries to the blood vessels and kidneys as well as long-term injuries, and remains the most important cause of maternal and neonatal death [1]. This complicated and serious pregnancy-related diseases is characterized by hypertension and proteinuria. Some cases of PE can uaually cooccur with gestational diabetes mellitus (GDM), for they may share common pathogrnrsis $[2,3]$ and cause damage to multiple organs in the human body even in cases when prior to pregnancy, both blood pressure or blood glucose and renal function were normal in these patients.

As PE proceeds during pregnancy, blood pressure may continue to increase to more than $160 / 110 \mathrm{mmHg}$, and the level of proteinuria may reach greater than $5000 \mathrm{mg} / 24$ $\mathrm{h}$, developing into severe preeclampsia (sPE). Additional symptoms may develop as well, including HELLP syndrome (hemolysis, elevated liver enzymes and low platelets syndrome), persistent headache, and even a choked optic disc, resulting in vision loss [4]. Including poor placental vascular invasion, decreased 2-methoxyestradiol level, abnormal proteomics expression, many factors have been identified to participate in the pathogenesis of PE [5-8], but no more detailed or exact mechanisms were found. Due to the unknown pathogenesis of $\mathrm{PE}$, prompt delivery of the fetus and placenta may be the only effective treatment in the later stages of the disease. Unfortunately, preterm delivery can result in further maternal and infant health problems. As a result, $\mathrm{PE}$, and especially sPE, exists as one of the most common causes of mortality during pregnancy, with an increasingly higher incidence rate. Additional research is urgently needed to foster a better understanding of the pathogenic mechanisms involved in PE.

From the previous papers, non-coding RNAs, such as miRNAs, play a vital role in PE. Circular RNAs (circRNAs) are a special type of non-coding RNA in mammalian cells that interact closely with miRNAs; thus, circRNAs have attracted increasing attention from researchers due to their distinctive ring frame, which is in contrast the more common linear structures. As circRNAs have no $5^{\prime}$ to $3^{\prime}$ polarity or polyadenylated tails $[9,10]$, they are immune to RNase and are expressed stably. circRNA expression is concentrated in some specific tissues or organs, particularly in the brain [11]. Most of the known circRNAs are produced from the back-splicing $[12,13]$ of exons through three main mechanisms, including lariat-driven circularization, intron-pairing-driven circularization and the selfcircularization of an intron to form circRNAs (ciRNAs) [14-16]. These features contribute to the performance of crucial physiological functions by circRNAs. Some specific circRNAs may have regulatory effects on gene expression [17] and human diseases, and some are correlated with the RNA binding protein Quaking [18]. The most well-known circRNA functions as a microRNA sponge by interacting with miRNA-7 [11, 19]. As research has progressed, circRNAs have been demonstrated to be associated with atherosclerosis, neurological disorders, diabetes and cancer [20-23]. However, few studies in the field of gynecology and obstetrics have identified their potential significance in the onset of PE.

In this study, we quantified the expression level of circRNAs and identified the role that circRNAs played in placental tissue during the development of PE to provide a new avenue of research regarding the pathological mechanisms of PE.

\section{Materials and Methods}

\section{Patients and sample collection}

All human placental tissue samples were obtained from the Nanjing Medical University Affiliated Nanjing Maternal and Child Health Hospital from February 2014 to January 2015 (Table 1). Overall, the study included 75 patients. To form the experimental group, 40 samples were collected from patients with severe preeclampsia at gestational weeks ranging from 30 to 34 and with levels of proteinuria ranging from $5000 \mathrm{mg} / 24 \mathrm{~h}$ to $11,700 \mathrm{mg} / 24 \mathrm{~h}$. The control group consisted of samples acquired from 35 healthy 


\section{Cellular Physiology Cell Physiol Biochem 2016;39:1380-1390 \begin{tabular}{ll|l} 
and Biochemistry Published online: September 08, 2016 & $\begin{array}{l}\text { ○ 2016 The Author(s). Published by S. Karger AG, Basel } \\
\text { www.karger.com/cpb }\end{array}$ \\
\hline
\end{tabular} \\ Qian et al.: Expression Difference of Placental circRNAs in Preeclampsia}

but premature births at 32.3 to 34 weeks gestation. Immediately following acquisition, the fresh placental tissue samples were placed in sterile, RNase-free $2.0 \mathrm{ml}$ centrifuge tubes. Then, the samples were minced and allowed to soak in TRIzol. After these steps, all 75 samples were stored at $-80{ }^{\circ} \mathrm{C}$.

Six placental tissue samples, including three PE samples and three control samples, were sent to KANGCHEN (Shanghai, China) for the Arraystar circRNA Microarray analysis. On the basis of the chip results, we picked out several circRNAs as the candidate validation genes due to their high levels in both groups and their significant fold changes. The final choice of the validation genes was determined by the practicability of the designed divergent primers, which are described in greater detail below.

\section{Total RNA extraction and reverse transcription}

According to the instructions, we extracted total RNA from the samples using TRIzol reagent (Invitrogen, Karlsruhe, Germany) and the RNAprep pure tissue kit (TIANGEN) (DP431) in a step-by-step manner. The integrity of the extracted RNA was tested via $1 \%$ agarose gel electrophoresis using the following criteria: there could be up to three bands; the ratio of $28 \mathrm{~S}$ rRNA/18 S rRNA should be 2; and the $5 \mathrm{~S}$ rRNA should not be too bright. The purity of the extracted RNA was measured by a UV spectrophotometer using the following criteria: the $260 / 280 \mathrm{~nm}$ absorbance ratio of the qualified sample should be between 1.8 and 2.1 , with 2.0 being considered best. According to the concentration of each sample, we added $1000 \mathrm{ng}$ to the $20 \mu \mathrm{l}$ reverse transcription system and then examined each sample using reverse transcription with random primers following the recommendations of the Thermo Scientific RevertAid First Strand cDNA Synthesis Kit.

\section{Regular-PCR (R-PCR) and annealing temperature determination}

Considering the unique ring structure of circRNAs, we designed corresponding divergent primers using Primer 3.0 according to the sequences provided by the microarray analysis results. These primers were synthesized by the Realgene Company (Nanjing, China). The integral internal reference gene we used was glyceraldehyde 3-phosphate dehydrogenase (GAPDH). The primers were designed to amplify a target sequence with a length of approximately $200 \mathrm{bp}$. Based on the instructions for Taq DNA Polymerase, we utilized 3 different temperature gradients $\left(56,59\right.$ and $\left.62^{\circ} \mathrm{C}\right)$ in a $25 \mu \mathrm{l}$ reaction system.

The thermal cycling conditions were as follows: start at $94^{\circ} \mathrm{C}$ for 5 mins; 30 cycles of $94{ }^{\circ} \mathrm{C}$ for $30 \mathrm{~s}$, a pre-selected annealing temperature for $30 \mathrm{~s}$, and $72{ }^{\circ} \mathrm{C}$ for $30 \mathrm{~s}$; and maintenance at $72{ }^{\circ} \mathrm{C}$ for 10 mins for

Table 1. General features of the pregnant women in the two groups. NS, non-significant difference

\begin{tabular}{lllc}
\hline & Preeclampsia $(\mathrm{n}=40)$ & Control $(\mathrm{n}=35)$ & p-value \\
\hline Age (years) & $30.79 \pm 3.68$ & $30.30 \pm 3.44$ & 0.1853 \\
Height $(\mathrm{cm})$ & $161.47 \pm 4.86$ & $162.18 \pm 4.41$ & 0.7585 \\
Weight $(\mathrm{kg})$ & $79.11 \pm 13.53$ & $78.77 \pm 7.23$ & 0.3373 \\
Gestational week & $33.53 \pm 1.56$ & $33.15 \pm 0.89$ & 0.2615 \\
Proteinuria level $(\mathrm{mg} / 24 \mathrm{~h})$ & $8412.63 \pm 1793.27$ & $1382.23 \pm 873.45$ & 0.0034 \\
Systolic pressure $(\mathrm{mmHg})$ & $165.55 \pm 19.84$ & $113.27 \pm 6.17$ & 0.0002 \\
Diastolic pressure $(\mathrm{mmHg})$ & $105.36 \pm 10.87$ & $70.91 \pm 6.35$ & 0.0026 \\
ALT / AST & $0.66 \pm 0.27$ & $0.65 \pm 0.14$ & 0.9843 \\
PLT $\left(10^{\wedge}\right.$ /L) & $158.81 \pm 59.25$ & $201.23 \pm 72.03$ & 0.9321 \\
Mode of delivery & $\mathrm{C}$-sect & $\mathrm{C}$-sect & NS \\
Neonatal weight (g) & $2292.50 \pm 781.44$ & $3300.00 \pm 324.04$ & 0.0003 \\
Neonatal Apgar score & $9.68 \pm 0.69$ & 10 & 0.0885 \\
\hline
\end{tabular}

Table 2. Sequence of the internal reference and the paired primers

\begin{tabular}{lll}
\hline & \multicolumn{1}{c}{ 5'-3' (sense) } & \multicolumn{1}{c}{ 5'-3' (antisense) } \\
\hline GAPDH & GAAGGTGAAGGTCGGAGTC & GAAGATGGTGATGGGATTTC \\
hsa_circRNA_100782 & TCATGCTGATCTCAAGCCAGA & ACCAAGACTTGTGAGGCCAT \\
hsa_circRNA_102682 & GTTTCTCTGAGTCCTGCCCT & GGATTGCTGCAGGTTCGAAT \\
hsa_circRNA_104820 & CCGTTGCTGACTATGTACGC & TCATACGCAACCAAGCCATG \\
\hline
\end{tabular}




\section{Cellular Physiology Cell Physiol Biochem 2016;39:1380-1390 \begin{tabular}{ll|l} 
and Biochemistry & Dublished online: September 08, 2016 & $\begin{array}{l}\text { @ 2016 The Author(s). Published by S. Karger AG, Basel } \\
\text { www.karger.com/cpb }\end{array}$ \\
\hline
\end{tabular}}

Qian et al.: Expression Difference of Placental circRNAs in Preeclampsia

full extension. The products of R-PCR were examined using 1.5\% agarose gel electrophoresis under the following criteria: there should be only one band in the lane of the specific annealing temperature, and if there was one band in more than one lane, the brightest band was chosen; no existence of primer dimers or by-products; and compared to the DNA marker, the molecular weight must be equal to the size of the target fragment (approximately $200 \mathrm{bp}$ ). Finally, combining all the conditions above, three ideal up-regulated genes, hsa_circRNA_100782 (FC = 3.71), hsa_circRNA_102682 (FC = 3.59) and hsa_circRNA_104820 (FC = 5.96) were selected as the validation genes. Table 2 contains the sequences of the paired primers we designed. The best annealing temperatures were $59{ }^{\circ} \mathrm{C}$ for hsa_circRNA_100782 and hsa_circRNA_102682 and $56^{\circ} \mathrm{C}$ for GAPDH and hsa_circRNA_104820.

\section{qRT-PCR detection of target genes}

Once the annealing temperature of each gene was identified, qRT-PCR was performed with SYBR. To eliminate the experimental random error, samples were loaded in triplicate and each well was treated identically. The data were analyzed using the $2^{-\Delta \Delta t}$ method; to guarantee the accuracy of the results, all data are represented as the means \pm SD of three independent experiments.

\section{Statistical analyses}

To analyze the complex and tedious data, both Statistical Program for Social Sciences Version 22 (SPSS) and GraphPad Prism 5.0 were utilized simultaneously. In addition, a $t$-test was also used to estimate the data, and $\mathrm{p} \leq 0.05$ was used to denote statistical significance. To determine the significance of these data for preeclampsia, we also established a receiver operating characteristic (ROC) curve for each circRNA. The area under the curve (AUC) was calculated for each respective circRNA.

\section{Results}

Characteristics of the study population

In total, 40 placenta samples of patients with PE and 35 placenta samples from corresponding premature births were collected in our study. The patients' characteristics are summarized in Table 1 . No differences were observed between the two groups regarding age, height, weight, gestational week, ALT/AST, PLT, mode of delivery or the neonatal Apgar score $(\mathrm{p}>0.05)$. However, the $24 \mathrm{~h}$ proteinuria, blood pressure and neonatal weight were

Fig. 1. Detection results of all circRNAs. a. Scatter Plots The values for the $\mathrm{X}$ and $\mathrm{Y}$ axes are normalized signal values (log2 scaled). The green lines represent fold change lines. circRNAs above the top green line and below the bottom green line indicated more than a 2.0-fold change of circRNAs between the two groups. b. Volcano Plots The red point in the plot represents the differentially expressed circRNAs that were statistically significant. c. Histogram Considering the fold change and p-value, a total of 301 circRNAs were detected, of which 143 were up-regulated and 158 were down-regulated.

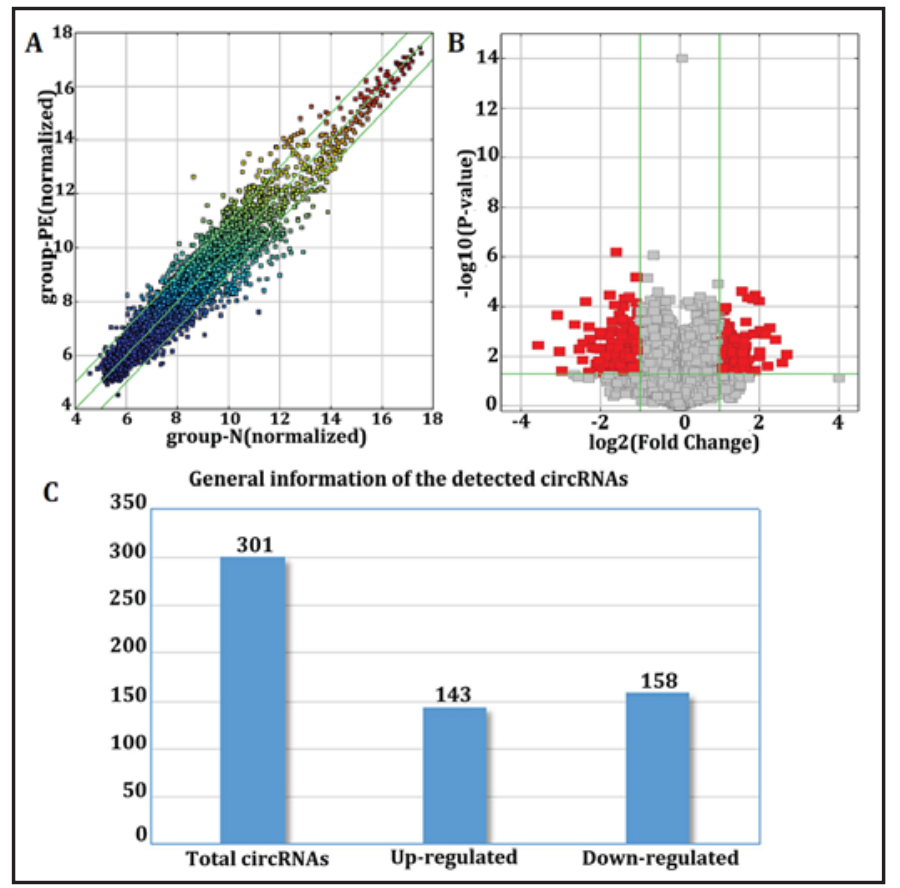



Cellular Physiology Cell Physiol Biochem 2016;39:1380-1390 \begin{tabular}{ll|l} 
and Biochemistry & DOI: 10.1159/000447842 & $\begin{array}{l}\text { O 2016 The Author(s). Published by S. Karger AG, Basel } \\
\text { www.karger.com/cpb }\end{array}$ \\
\cline { 2 - 3 }
\end{tabular} Qian et al.: Expression Difference of Placental circRNAs in Preeclampsia

Table 3. List of circRNAs with significant differences between two groups (FC>3.0)

\begin{tabular}{|c|c|c|c|c|c|c|c|}
\hline circRNA & Regulation & Fold Change & p-value & chrom & strand & txStart & txEnd \\
\hline hsa_circRNA_104893 & up & 3.00 & 0.00715887 & $\operatorname{chr} 9$ & + & 118969734 & 119033695 \\
\hline hsa_circRNA_102650 & up & 3.01 & 0.017272762 & chr2 & + & 26587169 & 26598016 \\
\hline hsa_circRNA_104891 & up & 3.02 & 0.017547647 & $\operatorname{chr} 9$ & + & 118969734 & 118989831 \\
\hline hsa_circRNA_103667 & up & 3.02 & 0.011978023 & chr4 & - & 77055327 & 77065626 \\
\hline hsa_circRNA_104682 & up & 3.05 & 0.002392826 & chr8 & - & 125332326 & 125343033 \\
\hline hsa_circRNA_104892 & up & 3.06 & 0.005049701 & chr9 & + & 118969734 & 118997916 \\
\hline hsa_circRNA_101900 & up & 3.08 & 0.033676024 & $\operatorname{chr} 16$ & + & 88008653 & 88017865 \\
\hline hsa_circRNA_001695 & up & 3.08 & 0.03159226 & chr20 & + & 58755107 & 58755971 \\
\hline hsa_circRNA_103618 & up & 3.10 & 0.027353647 & chr4 & - & 36230203 & 36231267 \\
\hline hsa_circRNA_102680 & up & 3.11 & 0.007328049 & chr2 & + & 36623756 & 36706837 \\
\hline hsa_circRNA_100921 & up & 3.15 & 0.032709009 & $\operatorname{chr} 11$ & - & 85707868 & 85718626 \\
\hline hsa_circRNA_102677 & up & 3.15 & 0.001446147 & chr2 & + & 36623756 & 36623930 \\
\hline hsa_circRNA_104547 & up & 3.16 & 0.000403266 & chr7 & - & 158552176 & 158557544 \\
\hline hsa_circRNA_103489 & up & 3.16 & 0.003944009 & chr3 & + & 149563797 & 149613347 \\
\hline hsa_circRNA_102649 & up & 3.21 & 0.016766036 & $\operatorname{chr} 2$ & + & 26587169 & 26596497 \\
\hline hsa_circRNA_103487 & up & 3.26 & $4.17515 \mathrm{E}-05$ & chr3 & + & 149563797 & 149570383 \\
\hline hsa_circRNA_103492 & up & 3.30 & 0.012977941 & chr3 & + & 149563797 & 149639014 \\
\hline hsa_circRNA_103116 & up & 3.34 & 0.046724496 & $\operatorname{chr} 21$ & + & 30693541 & 30702014 \\
\hline hsa_circRNA_102682 & up & 3.59 & $4.83021 \mathrm{E}-05$ & chr2 & + & 36623756 & 36749456 \\
\hline hsa_circRNA_102681 & up & 3.62 & 0.001261817 & chr2 & + & 36623756 & 36744685 \\
\hline hsa_circRNA_100782 & up & 3.71 & 0.036767421 & $\operatorname{chr} 11$ & + & 33307958 & 33309057 \\
\hline hsa_circRNA_102679 & up & 3.72 & $3.41004 \mathrm{E}-05$ & chr2 & + & 36623756 & 36691798 \\
\hline hsa_circRNA_102678 & up & 3.97 & $5.75085 \mathrm{E}-05$ & chr2 & + & 36623756 & 36669878 \\
\hline hsa_circRNA_103493 & up & 4.00 & 0.010305698 & chr3 & + & 149613259 & 149639014 \\
\hline hsa_circRNA_104823 & up & 4.01 & 0.006571296 & chr9 & + & 96238537 & 96259881 \\
\hline hsa_circRNA_104700 & up & 4.07 & 0.000914974 & chr8 & - & 141710989 & 141716304 \\
\hline hsa_circRNA_104822 & up & 4.23 & 0.000895222 & $\operatorname{chr} 9$ & + & 96233422 & 96278551 \\
\hline hsa_circRNA_104824 & up & 4.43 & 0.001274347 & chr9 & + & 96238537 & 96261168 \\
\hline hsa_círcRNA_104981 & up & 4.60 & 0.024418528 & $\operatorname{chrX}$ & - & 10534927 & 10535643 \\
\hline hsa_circRNA_104819 & up & 4.80 & 0.00069232 & chr9 & + & 96233422 & 96238620 \\
\hline hsa_circRNA_103474 & up & 5.31 & 0.002076334 & chr3 & + & 130851588 & 130852800 \\
\hline hsa_circRNA_104820 & up & 5.96 & 0.018264734 & $\operatorname{chr} 9$ & + & 96233422 & 96259881 \\
\hline hsa_circRNA_104821 & up & 6.47 & 0.008384202 & $\operatorname{chr} 9$ & + & 96233422 & 96261168 \\
\hline hsa_circRNA_104075 & down & 3.03 & 0.024352363 & $\operatorname{chr} 6$ & - & 17669523 & 17669777 \\
\hline hsa_circRNA_100021 & down & 3.04 & $6.2365 \mathrm{E}-07$ & chr1 & - & 5987708 & 6022009 \\
\hline hsa_circRNA_101722 & down & 3.05 & 0.008152406 & chr16 & + & 16146580 & 16150152 \\
\hline hsa_circRNA_100476 & down & 3.09 & 0.004771015 & chr1 & + & 230795209 & 230807386 \\
\hline hsa_circRNA_001216 & down & 3.09 & 0.000382127 & chr10 & + & 53459000 & 53459207 \\
\hline hsa_circRNA_400027 & down & 3.11 & $8.48125 \mathrm{E}-05$ & $\operatorname{chr} 15$ & + & 25325262 & 25326442 \\
\hline hsa_circRNA_104099 & down & 3.13 & 0.024218314 & chr6 & + & 35195356 & 35201078 \\
\hline hsa_circRNA_100117 & down & 3.17 & 0.015660628 & chr1 & - & 28362054 & 28384605 \\
\hline hsa_circRNA_103039 & down & 3.18 & 0.033397141 & chr20 & - & 33954359 & 33962059 \\
\hline hsa_circRNA_101803 & down & 3.22 & 0.001025761 & $\operatorname{chr} 16$ & - & 47143393 & 47165936 \\
\hline hsa_circRNA_100750 & down & 3.25 & 0.000882698 & chr11 & + & 3988781 & 4080626 \\
\hline hsa_circRNA_104109 & down & 3.25 & 0.000375716 & chr6 & + & 42819829 & 42821476 \\
\hline hsa_circRNA_000799 & down & 3.28 & 0.002706406 & $\operatorname{chr} 11$ & + & 65266845 & 65267149 \\
\hline hsa_circRNA_102958 & down & 3.28 & 0.02506972 & chr2 & - & 239184383 & 239186596 \\
\hline hsa_circRNA_100860 & down & 3.28 & 0.004513648 & chr11 & + & 68115314 & 68115711 \\
\hline hsa_circRNA_100660 & down & 3.37 & 0.038814527 & $\operatorname{chr} 10$ & + & 99967857 & 99969656 \\
\hline hsa_circRNA_102550 & down & 3.40 & $3.37516 \mathrm{E}-05$ & chr19 & + & 41089303 & 41089623 \\
\hline hsa_circRNA_103781 & down & 3.47 & 0.001295906 & chr5 & + & 896779 & 901546 \\
\hline hsa_circRNA_101861 & down & 3.65 & 0.021670739 & chr16 & - & 70294946 & 70302282 \\
\hline hsa_circRNA_400066 & down & 3.65 & 0.009461681 & chr22 & - & 19965129 & 19965469 \\
\hline hsa_circRNA_104872 & down & 3.79 & 0.019917377 & chr9 & - & 114860749 & 114864565 \\
\hline hsa_circRNA_000993 & down & 3.80 & 0.015349172 & chr9 & - & 125930467 & 125936121 \\
\hline hsa_circRNA_102195 & down & 3.92 & 0.001464989 & $\operatorname{chr} 17$ & + & 73808192 & 73809959 \\
\hline hsa_circRNA_101740 & down & 3.98 & 0.004539618 & chr16 & + & 19619499 & 19628130 \\
\hline hsa_circRNA_104423 & down & 4.00 & 0.001072232 & chr7 & + & 90355880 & 90356126 \\
\hline hsa_circRNA_001950 & down & 4.00 & 0.04480486 & $\operatorname{chr} 11$ & - & 3177371 & 3177731 \\
\hline hsa_circRNA_102774 & down & 4.01 & 0.026505596 & chr2 & - & 85625142 & 85626408 \\
\hline hsa_circRNA_101846 & down & 4.03 & 0.005101387 & chr16 & + & 68893786 & 68896964 \\
\hline hsa_circRNA_400095 & down & 4.11 & 0.014954005 & chr9 & + & 116764513 & 116764813 \\
\hline hsa_circRNA_103307 & down & 4.30 & 0.004687443 & chr3 & - & 18456602 & 18462483 \\
\hline hsa_circRNA_100876 & down & 4.31 & 0.018936472 & $\operatorname{chr} 11$ & + & 71668272 & 71671937 \\
\hline hsa_circRNA_101877 & down & 4.61 & 0.004592684 & $\operatorname{chr} 16$ & - & 74670243 & 74671868 \\
\hline hsa_circRNA_001109 & down & 4.80 & 0.001979339 & chr2 & - & 100721965 & 100754399 \\
\hline hsa_circRNA_101945 & down & 4.85 & 0.044180868 & chr17 & - & 2195845 & 2196271 \\
\hline hsa_circRNA_104551 & down & 4.88 & 0.00063567 & chr8 & + & 9437668 & 9437893 \\
\hline hsa_circRNA_000031 & down & 4.91 & 0.046623197 & $\operatorname{chr} 1$ & + & 2225564 & 2225807 \\
\hline hsa_circRNA_104126 & down & 5.17 & 5.99233E-05 & chr6 & - & 53365044 & 53365148 \\
\hline hsa_circRNA_100269 & down & 5.40 & 0.002952801 & $\operatorname{chr} 1$ & + & 82302569 & 82372915 \\
\hline hsa_circRNA_104873 & down & 5.47 & 0.013811499 & chr9 & - & 114860749 & 114875148 \\
\hline hsa_circRNA_102533 & down & 5.76 & 0.005009807 & $\operatorname{chr} 19$ & + & 34942885 & 34957919 \\
\hline hsa_circRNA_100477 & down & 6.25 & 0.000525415 & $\operatorname{chr} 1$ & + & 230798886 & 230807386 \\
\hline hsa_circRNA_104342 & down & 7.83 & 0.038947537 & $\operatorname{chr} 7$ & + & 33185853 & 33217203 \\
\hline hsa_circRNA_104166 & down & 8.18 & 0.006226957 & chr6 & - & 105563560 & 105573453 \\
\hline hsa_circRNA_104916 & down & 8.47 & 0.000217748 & chr9 & + & 127064214 & 127089724 \\
\hline hsa_circRNA_103519 & down & 11.86 & 0.003573195 & chr3 & + & 179045348 & 179046139 \\
\hline
\end{tabular}




\section{Cellular Physiology Cell Physiol Biochem 2016;39:1380-1390 \begin{tabular}{ll|l} 
and Biochemistry & Published online: September 08, 2016 & $\begin{array}{l}\text { (0) 2016 The Author(s). Published by S. Karger AG, Basel } \\
\text { www.karger.com/cpb }\end{array}$
\end{tabular}

Fig. 2. Image showing testing of qRT-PCR products on a $1.5 \%$ agarose gel. The molecular weight of the marker is 10,000 . According to the markers, the molecular weights of the target genes were approximately 200 - $250 \mathrm{bp}$. Only one band was present in each lane. In comparison, the bands in the control samples were not as bright as their corresponding PE samples, which shows the differential circRNA expression levels between PE samples and controls.
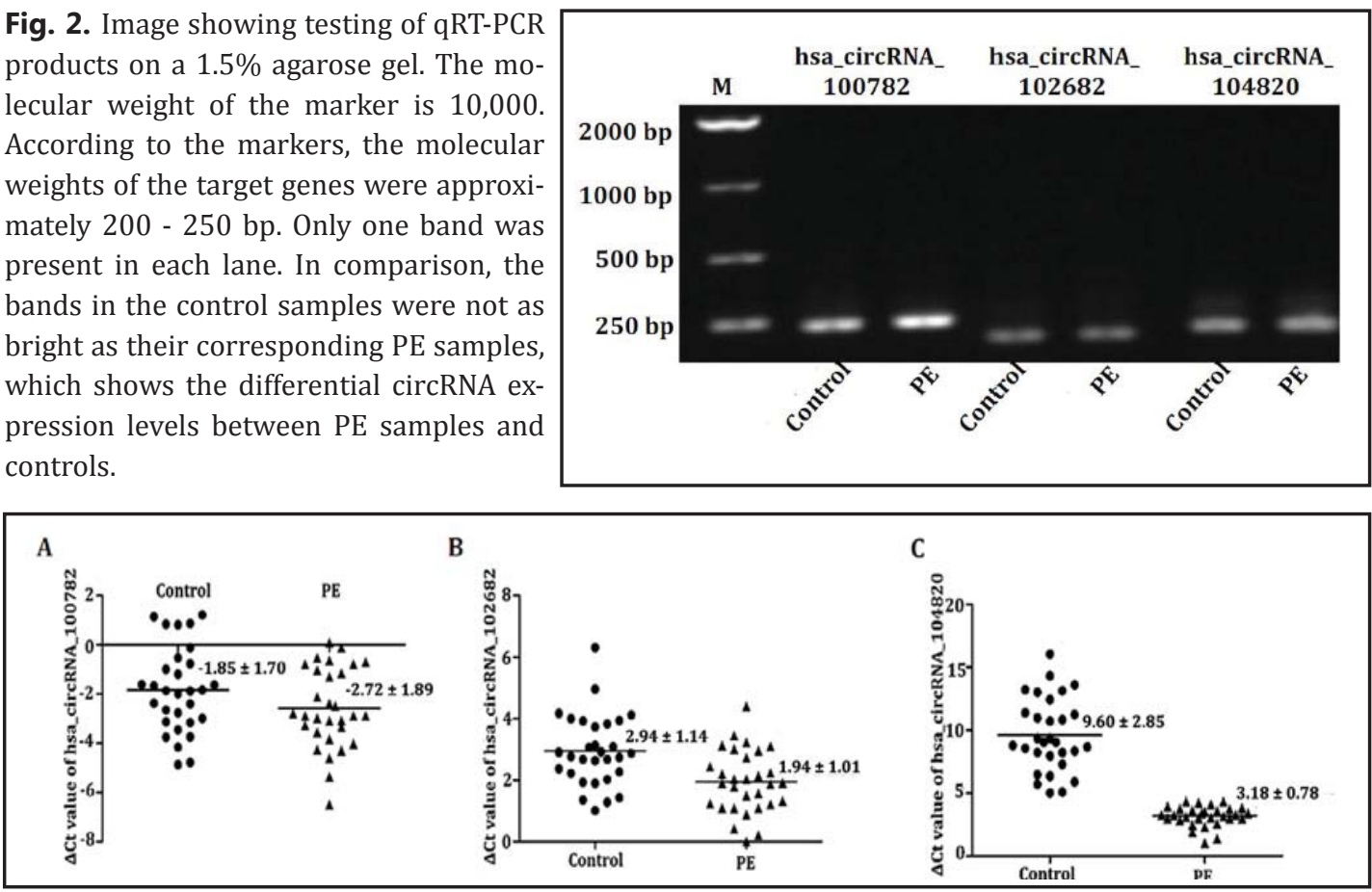

Fig. 3. The expression levels of circular RNAs in patients with PE and patients who delivered prematurely. The expression levels of hsa_circRNA_100782, hsa_circRNA_102682 and hsa_circRNA_104820 in each patient were compared. Higher $\Delta \mathrm{Ct}$ values indicate lower levels of expression. The expression levels of each gene were significantly higher versus their controls; all p-values $<0.05$.

significantly different between the two groups $(\mathrm{p}<0.01)$.

\section{Results of the microarray analysis}

We accounted for the fold change (FC $\geq 2.0$ ) and p-values $(\leq 0.05)$ in this analysis. The expression of specific circRNAs was significantly different between groups. The general information pertaining to the detected circRNAs is shown in Figure 1. Altogether, 301 differentially expressed circRNAs were identified, of which 143 were up-regulated and 158 were down-regulated. Certain circRNAs with highly differential levels of expression are shown in Table 3 (FC $\geq 3.0$ ).

\section{Evaluation of primers and products}

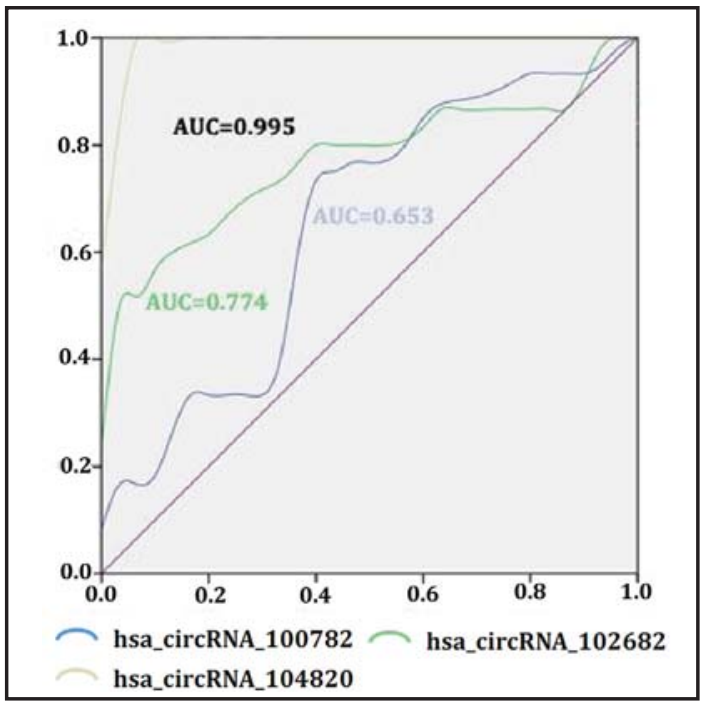

Fig. 4. The ROC curves for the three circRNAs.

To increase the rigor of the study and to enhance the efficacy of the primers that we designed, we measured both the specificity and sensitivity of the amplification products. After qRT-PCR, $1.5 \%$ agarose gel electrophoresis was used to test the uniqueness of the products and the relative amounts between the experimental and control groups (Fig. 2). According to the electrophoresis bands, only the targeted products and no primer dimers or non-specific amplification products were present, indicating that the divergent primers utilized for the circRNAs were effective and appropriate. The data in Figure 3 and the band brightness in Figure 2 show that the circRNA levels were significantly higher in PE group. 


\section{Cellular Physiology Cell Physiol Biochem 2016;39:1380-1390 \\ \begin{tabular}{ll|l} 
and Biochemistry & Dublished online: September 08, 2016 & $\begin{array}{l}\text { ○ 2016 The Author(s). Published by S. Karger AG, Basel } \\
\text { www.karger.com/cpb }\end{array}$ \\
\cline { 2 - 4 }
\end{tabular} \\ Qian et al.: Expression Difference of Placental circRNAs in Preeclampsia}

Values of circRNA in PE

These validation results agreed with the ROC curves (Fig. 4). The potential role of circRNAs in the pathogenesis of PE is of great importance. Furthermore, the area under the ROC curve for hsa_circRNA_100782, hsa_circRNA_102682 and hsa_circRNA_104820 were $0.653,0.774$ and 0.995 , respectively.

\section{Discussion}

circRNAs differ substantially from conventional linear RNAs and have recently become an important research topic due to their stable structures and high degrees of tissue specificity. circRNAs were first accidently observed in RNA viruses and were regarded as splicing errors or by-products during the onset of splicing $[9,12]$ despite having been observed for decades in eukaryotic cells. While previously limited by existing technology, circRNA research has emerged as an important research topic only in recent years. circRNAs have highly conserved sequences and stable expression in different individuals [15]; these futures hint at their potential to mediate the occurrence of specific diseases in the absence of an external environment influence.

Exonic circRNAs might have extraordinary effects in cellular physiology, including miRNA binding, translational regulation, protein interactions, and even protein translation (found only in viruses) [23]. Additional studies have noted that circRNAs can function as miRNA sponges, which is to say circRNAs have many miRNA binding sites that competitively bind to miRNAs. Thus, circRNAs may alleviate the inhibitory effects of miRNAs on target molecules, thereby regulating gene expression levels. The most widely studied molecular sponge is antisense to the cerebellar degeneration-related protein 1 transcript (CDR1as), which is located in the brains of humans and mice. CDR1as has approximately 74 miR-7 binding sites, and CDR1as over-expression can down-regulate miR-7 expression level [11, $14,16]$. This finding revealed a new therapeutic strategy for Alzheimer's disease.

The circRNAs isolated from the placental tissues of PE patients in our study also have several miRNA binding sites [24], and some even were associated with two different diseases like PE and gestational diabetes mellitus[25]. As shown in Table 4, many circRNAs have miRNA-17 binding sites, suggesting that these circRNAs can regulate the expression level of miRNA-17 in human placental tissues. miRNA-17 has been identified as one of the angiogenesis-associated miRNAs in the human placenta and was found to be highly expressed in PE placentas [30]. In the work of Chen and Wang [24] and Wang et al. [30], up-regulated miRNA-17 in the placenta could advance the process of PE by targeting the ephrin-B2/Eph receptor B4 (EPHB4) system, a classical pathway involved in trophoblast invasion; notably, the disorganization of this system exacerbates the process during PE. The differential expression of circRNAs could possibly up-regulate the expression levels of miRNA-17 through miRNA sponges, thereby contributing to the pathogenesis of PE. This possibility warrants further investigation.

The fact that the miRNA binding sites of miRNA-17 are strongly related to the onset of PE is not a peculiar phenomenon, and from Table 4, we can tell that many other MREs of other circRNAs also play an important role in PE. These results suggested that the sponge functions of circRNAs may be highly significant and thus deserve further investigation. Despite the miRNA sponge functions, the interaction of proteins in blood corpuscles should also be mentioned. Recently, the work of Zhang et al. [31] showed that one plasma protein factor, endoglin (ENG), can combine with the up-regulated circRNA_101222 in blood corpuscles of preeclampsia patients; this combination of circRNA and ENG may be a potential biomarker for the early prediction and diagnosis of PE. While this finding reveals new information for researchers, further study is still warranted in the future.

It is believed that when PE occurs, the deficiency of placental trophoblast invasion may cause reduced placental flow and, eventually, placental ischemia, which is the initiating agent for subsequent disorders. Ischemia accompanied by hypoxia raises a series of complications 


\section{Cellular Physiology Cell Physiol Biochem 2016;39:1380-1390 \begin{tabular}{ll|l} 
DOI: $10.1159 / 000447842$ & 2016 The Author(s). Published by S. Karger AG, Basel \\
and Biochemistry Published online: September 08, 2016 & $\begin{array}{l}\text { O } \\
\text { www.karger.com/cpb }\end{array}$ \\
\cline { 2 - 3 }
\end{tabular}

Table 4. List of PE incidence-related miRNAs in placenta. miRNAs in bold were shown to participate in the pathogenesis of PE via different pathways in the placenta. Their references are given in brackets

\begin{tabular}{|c|c|c|c|c|}
\hline miRNA Binding Sites & circRNA & Regulation & Fold Change & Target \\
\hline \multirow[t]{13}{*}{ hsa-miR-17-3p[24] } & hsa_circRNA_101289 & up & 2.0245 & VEGFA, EFNB2, EPHB4 \\
\hline & hsa_circRNA_102390 & up & 2.0368 & \\
\hline & hsa_circRNA_101608 & up & 2.1259 & \\
\hline & hsa_circRNA_101611 & up & 2.1303 & \\
\hline & hsa_circRNA_102685 & up & 2.5299 & \\
\hline & hsa_circRNA_102683 & up & 2.8964 & \\
\hline & hsa_circRNA_100782 & up & 3.7106 & \\
\hline & hsa_circRNA_102679 & up & 3.7227 & \\
\hline & hsa_circRNA_102678 & up & 3.9735 & \\
\hline & hsa_circRNA_103285 & down & 2.1379 & \\
\hline & hsa_circRNA_101568 & down & 2.1406 & \\
\hline & hsa_circRNA_101695 & down & 2.2970 & \\
\hline & hsa_circRNA_104166 & down & 8.1805 & \\
\hline hsa-miR-152-3p[24] & hsa_circRNA_100181 & down & 2.5581 & HLA-G \\
\hline hsa-miR-155-5p[24-26] & hsa_circRNA_102719 & up & 2.0041 & Cyclin D1 \\
\hline \multirow[t]{2}{*}{ hsa-miR-210-5p[14,24-26] } & hsa_circRNA_400068 & up & 2.1154 & ISCU, EFNA3, homeobox-A9, HSD17B1 \\
\hline & hsa_circRNA_001096 & down & 2.2375 & \\
\hline hsa-miR-222-5p[25,26] & hsa_circRNA_101784 & down & 2.2515 & P57, FOXO, TIMP3, MMP1, SOD2, KIT \\
\hline \multirow[t]{2}{*}{ hsa-miR-29a-3p $[25,26]$} & hsa_circRNA_100291 & up & 2.1439 & Insig1, PCK2 \\
\hline & hsa_circRNA_400059 & down & 2.5877 & \\
\hline \multirow[t]{4}{*}{ hsa-miR-29a-5p $[25,26]$} & hsa_circRNA_102719 & up & 2.0041 & Insig1, PCK2 \\
\hline & hsa_circRNA_100225 & up & 2.0162 & \\
\hline & hsa_circRNA_102823 & up & 2.1090 & \\
\hline & hsa_circRNA_103689 & down & 2.0472 & \\
\hline \multirow[t]{2}{*}{ hsa-miR-519d-3p[25,26] } & hsa_circRNA_101462 & up & 2.0475 & CDKN1A/p21, PTEN, AKT3, TIMP2 \\
\hline & hsa_circRNA_101463 & up & 2.5327 & \\
\hline \multirow[t]{2}{*}{ hsa-miR-15b-3p $[25,26]$} & hsa_circRNA_101611 & up & 2.1303 & CCNE1 \\
\hline & hsa_circRNA_100845 & down & 2.6807 & \\
\hline \multirow[t]{3}{*}{ hsa-miR-15b-5p[25,26] } & hsa_circRNA_104681 & up & 2.9562 & CCNE1 \\
\hline & hsa_circRNA_104682 & up & 3.0469 & \\
\hline & hsa_circRNA_101852 & down & 2.3583 & \\
\hline hsa-miR-223-3p[25,26] & hsa_circRNA_103039 & down & 3.1797 & GZMB, STAT3, E2F1, FOXO1 \\
\hline \multirow[t]{2}{*}{ hsa-miR-223-5p $[25,26]$} & hsa_circRNA_104810 & up & 2.6023 & GZMB, STAT3, E2F1, FOXO1 \\
\hline & hsa_circRNA_100181 & down & 2.5581 & \\
\hline hsa-miR-26a-1-3p[25,26] & hsa_circRNA_100660 & down & 3.3707 & Bcl-2, Mcl-1, CCND, MMP2 \\
\hline hsa-miR-26a-2-3p $[25,26]$ & hsa_circRNA_104563 & up & 2.6390 & Bcl-2, Mcl-1, CCND, MMP2 \\
\hline \multirow[t]{3}{*}{ hsa-miR-26a-5p[25,26] } & hsa_circRNA_104823 & up & 4.0147 & Bcl-2, Mcl-1, CCND, MMP2 \\
\hline & hsa_circRNA_104824 & up & 4.4342 & \\
\hline & hsa_circRNA_104819 & up & 4.7952 & \\
\hline hsa-miR-26b-3p[25,26] & hsa_circRNA_103116 & up & 3.3351 & SLC7A11 \\
\hline & hsa_circRNA_104126 & down & 5.1660 & \\
\hline & hsa_circRNA_103149 & down & 2.3110 & \\
\hline hsa-miR-136-3p $[25,26]$ & hsa_circRNA_100750 & down & 3.2472 & AEG-1, Bcl-2 \\
\hline hsa-miR-136-5p[25,26] & hsa_circRNA_104556 & up & 2.6705 & AEG-1, Bcl-2 \\
\hline & hsa_circRNA_100720 & down & 2.0446 & \\
\hline & hsa_circRNA_103149 & down & 2.3110 & \\
\hline & hsa_circRNA_101803 & down & 3.2246 & \\
\hline & hsa_circRNA_100876 & down & 4.3141 & \\
\hline hsa-miR-16-2-3p[25,26] & hsa_circRNA_104075 & down & 3.0258 & BCL2 \\
\hline hsa-miR-16-1-3p[25,26] & hsa_circRNA_104075 & down & 3.0258 & BCL2 \\
\hline hsa-miR-16-5p[25,26] & hsa_circRNA_101852 & down & 2.3583 & $\mathrm{BCL} 2$ \\
\hline & hsa_circRNA_101853 & down & 2.3850 & \\
\hline hsa-miR-181a-5p[25,26] & hsa_circRNA_101766 & down & 2.7519 & BCL-2, Tcl1 \\
\hline hsa-miR-181a-2-3p $[25,26]$ & hsa_circRNA_001416 & down & 2.8290 & BCL-2, Tcl1 \\
\hline hsa-miR-181a-3p[26] & hsa_circRNA_104253 & up & 2.0196 & BCL-2, Tcl1 \\
\hline & hsa_circRNA_101066 & up & 2.3439 & \\
\hline hsa-miR-21-3p[26] & hsa_circRNA_103205 & up & 2.1452 & PTEN, TPM1, BCL2 \\
\hline hsa-miR-21-5p[26] & hsa_circRNA_104574 & up & 2.0468 & PTEN, TPM1, BCL2 \\
\hline hsa-miR-26a-2-3p[26] & hsa_circRNA_101618 & up & 2.4874 & Bcl-2, Mcl-1, CCND, MMP2 \\
\hline hsa-miR-1-3p[26] & hsa_circRNA_104822 & up & 4.2287 & $\mathrm{JCN}$ \\
\hline & hsa_circRNA_002042 & down & 2.4405 & \\
\hline hsa-miR-584-3p[27] & hsa_circRNA_400066 & down & 3.6520 & eNOS \\
\hline hsa-miR-584-5p[27] & hsa_circRNA_100477 & down & 6.2461 & eNOS \\
\hline hsa-miR-335-3p[27] & hsa_circRNA_100039 & up & 2.0422 & eNOS \\
\hline & hsa_circRNA_000799 & down & 3.2752 & \\
\hline & hsa_circRNA_102219 & down & 2.0709 & \\
\hline hsa-miR-335-5p[27] & hsa_circRNA_101320 & down & 2.5180 & eNOS \\
\hline hsa-miR-141-5p[28] & hsa_circRNA_100431 & up & 2.3484 & JEG-3, HTR-8/SVneo \\
\hline & hsa_circRNA_104700 & up & 4.0670 & \\
\hline & hsa_circRNA_102599 & down & 2.3641 & \\
\hline & hsa_circRNA_101706 & down & 2.6574 & \\
\hline & hsa_circRNA_103456 & down & 2.8941 & \\
\hline hsa-miR-193b-3p[29] & hsa_circRNA_104939 & down & 2.5029 & HTR-8/SVneo \\
\hline & hsa_circRNA_400066 & down & 3.6520 & \\
\hline & hsa_circRNA_102195 & down & 3.9196 & \\
\hline
\end{tabular}




\section{Cellular Physiology Cell Physiol Biochem 2016;39:1380-1390 \begin{tabular}{ll|l} 
DOI: 10.1159/000447842 & $\begin{array}{l}\text { O 2016 The Author(s). Published by S. Karger AG, Basel } \\
\text { www.karger.com/cpb }\end{array}$ \\
\hline
\end{tabular} \\ Qian et al.: Expression Difference of Placental circRNAs in Preeclampsia}

regarding placental function, and some virulence factors are released into the blood. Therefore, the placenta is both the start and center of all the mechanisms responsible for PE. As the expression of circRNAs may differ between the placenta and the peripheral blood [32], we utilized placental tissues rather than serum in our study for a more circumstantial research.

Our study has some limitations. First, the sample selection was limited by a small number of PE samples, which was not large enough to establish definitive conclusions. Moreover, the choice of samples may not be generalizable to the general population. In future works, more samples should be collected to perform a detailed study. Equally important is that the samples were all collected from one hospital in a single year, which may have resulted in regional differences. Second, the study of circRNAs in PE has just started, and the functional analysis is imperfect; more work should be done to improve this shortcoming in the future. Through further study regarding the functions of circRNAs, our understanding of circRNA-related mechanisms of diseases could be improved, and the diagnostic accuracy and development of alternative prevention methods could be enhanced. Third, the expression of circRNAs in peripheral blood is essential for finding a suitable biomarker for earlier diagnoses of PE. In future studies, we also plan to analyze blood samples.

$\mathrm{PE}$ is an agnogenic disease occurring in pregnant women that primarily causes renal damage. PE cannot be identified until clinical manifestation becomes apparent, which is usually too late for clinical intervention measures. Thus, there is an urgent need to discover an ideal biomarker for PE before the condition progresses beyond the point of treatment. We hope that our research will open up new research directions regarding the pathogenesis of $\mathrm{PE}$ and will foster the development of effective breakthroughs.

To conclude, to identify the role that circRNAs play in PE placental tissues, our study analyzed the content of circRNAs in both patients with PE and patients who delivered prematurely. The results indicated that circRNAs expression differed significantly between the two groups and that circRNAs may have an important function as miRNA sponges. Our research represents a new breakthrough in the pathogenesis of PE. Of course, more work is needed to further uncover the molecular mechanisms of circRNAs and to reveal their deeper involvement in disease pathogenesis.

\section{Acknowledgments}

This study was supported by grants from the National Natural Science Foundation of China (No. 81571444, 81501341) and the Nanjing Medical Science and Technology Development Foundation (No. YKK15164).

\section{Disclosure Statement}

We declare that we have no financial and personal relationships with other individuals or organizations that can inappropriately influence our work. There are no professional or other personal interests of any nature or kind in any product, service and/or company that could be construed as influencing the position presented in, or the review of, the manuscript entitled "Potential Significance of Circular RNA in Human Placental Tissues for Patients with Preeclampsia".

\section{References}

1 Phipps E, Prasanna D, Brima W, Jim B: Preeclampsia: updates in pathogenesis, definitions, and guidelines. Clin J Am Soc Nephrol 2016;11:1102-1106.

2 Li j, Ying H, Cai, G, Guo Q Chen L: Pre-Eclampsia-Associated Reduction in Placental Growth Factor Impaired Beta Cell Proliferation Through PI3k Signalling. Cell Physiol Biochem 2015;36:34-43. 


\section{Cellular Physiology Cell Physiol Biochem 2016;39:1380-1390 \begin{tabular}{l|l|l}
\cline { 2 - 3 } DOI: 10.1159/000447842 & (C) 2016 The Author(s). Published by S. Karger AG, Basel
\end{tabular} and Biochemistry Published online: September 08, 2016 www.karger.com/cpb \\ Qian et al.: Expression Difference of Placental circRNAs in Preeclampsia}

3 Liu L, Zhang X, Rong C, Rui C, Ji H, Qian YJ, Jia R, Sun L: Distinct DNA methylomes of human placentas between pre-eclampsia and gestational diabetes mellitus. Cell Physiol Biochem 2014;34:1877-1889.

$4 \quad$ Pridjian G: Severe preeclampsia. Curr Womens Health Rev 2011;7:112-124.

5 Jia R, Li J, Rui C, Ji H, Ding H, Lu Y, De W, Sun L: Comparative Proteomic Profile of the Human Umbilical Cord Blood Exosomes between Normal and Preeclampsia Pregnancies with High-Resolution Mass Spectrometry. Cell Physiol Biochem 2015;36:2299-2306.

6 Li H, Han L, Yang Z, Huang W, Zhang X, Gu Y, Li Y, Liu X, Zhou L, Hu J, Yu M, Yang J, Li Y, Zheng Y, Guo J, Han J, Li L: Differential Proteomic Analysis of Syncytiotrophoblast Extracellular Vesicles from Early-Onset Severe Preeclampsia, using 8-Plex iTRAQ Labeling Coupled with 2D Nano LC-MS/MS. Cell Physiol Biochem 2015;36:1116-1130.

7 Shen Z, Wu Y, Chen X, Chang X, Zhou Q, Zhou J, Ying H, Zheng J, Duan T, Wang K: Decreased maternal serum 2-methoxyestradiol levels are associated with the development of preeclampsia. Cell Physiol Biochem 2014;34:2189-2199.

8 Jia RZ, Ding GC, Gu CM, Huang T, Rui C, Wang YX, Lu Q: CDX2 enhances HTR-8/SVneo trophoblast cell invasion by altering the expression of matrix metalloproteinases. Cell Physiol Biochem 2014;34:628-636.

9 Memczak S, Jens M, Elefsinioti A, Torti F, Krueger J, Rybak A, Maier L, Mackowiak SD, Gregersen LH, Munschauer M, Loewer A, Ziebold U, Landthaler M, Kocks C, le Noble F, Rajewsky N: Circular RNAs are a large class of animal RNAs with regulatory potency. Nature 2013;495:333-342.

10 Ledford H: Circular RNAs throw genetics for a loop. Nature 2013;494:415.

11 Rybak-Wolf A, Stottmeister C, Glazar P, Jens M, Pino N, Giusti S, Hanan M, Behm M, Barok O, Ashwal-Fluss R, Herzog M, Schreyer L, Papavasileiou P, Ivanov A, Ohman M, Refojo D, Kadener S, Rajewsky N: Circular RNAs in the mammalian brain Are highly abundant, conserved, and dynamically expressed. Mol Cell 2015;58:870-885.

12 Vicens Q, Westhof E: Biogenesis of circular RNAs. Cell 2014;159:13-14.

13 Chen I, Chen CY, Chuang TJ: Biogenesis, identification, and function of exonic circular RNAs. Wiley Interdiscip Rev RNA 2015;6:563-579.

14 Zhang Y, Fei M, Xue G, Zhou Q, Jia Y, Li L, Xin H, Sun S: Elevated levels of hypoxia-inducible microRNA-210 in pre-eclampsia: new insights into molecular mechanisms for the disease. J Cell Mol Med 2012;16:249-259.

15 Jeck WR, Sorrentino JA, Wang K, Slevin MK, Burd CE, Liu J, Marzluff WF, Sharpless NE: Circular RNAs are abundant, conserved, and associated with ALU repeats. RNA 2013;19:141-157.

16 Qu S, Yang X, Li X, Wang J, Gao Y, Shang R, Sun W, Dou K, Li H: Circular RNA: a new star of noncoding RNAs. Cancer Lett 2015;365:141-148.

17 Li Z, Huang C, Bao C, Chen L, Lin M, Wang X, Zhong G, Yu B, Hu W, Dai L, Zhu P, Chang Z, Wu Q Zhao Y, Jia Y, Xu P, Liu H, Shan G: Exon-intron circular RNAs regulate transcription in the nucleus. Nat Struct Mol Biol 2015;22:256-264.

18 Conn SJ, Pillman KA, Toubia J, Conn VM, Salmanidis M, Phillips CA, Roslan S, Schreiber AW, Gregory PA, Goodall GJ: The RNA binding protein quaking regulates formation of circRNAs. Cell 2015;160:1125-1134.

19 Jeck WR, Sharpless NE: Detecting and characterizing circular RNAs. Nat Biotechnol 2014;32:453-461.

20 Li P, Chen S: Using circular RNA as a novel type of biomarker in the screening of gastric cancer[J]. Clin Chim Acta 2015;444:132-136.

21 Wang X, Zhang Y, Huang L, Zhang J, Pan F, Li B, Yan Y, Jia B, Liu H, Li S, Zheng W: Decreased expression of hsa_circ_001988 in colorectal cancer and its clinical significances. Int J Clin Exp Pathol 2015;8:1602016025.

22 Li Y, Zheng Q Bao C, Li S, Guo W, Zhao J, Chen D, Gu J, He X, Huang S: Circular RNA is enriched and stable in exosomes: a promising biomarker for cancer diagnosis. Cell Res 2015;25:981-984.

23 Kos A, Dijkema R, Arnberg AC, van der Meide PH, Schellekens H: The hepatitis delta (delta) virus possesses a circular RNA. Nature 1986;323:558-560.

24 Chen DB, Wang W: Human placental microRNAs and preeclampsia. Biol Reprod 2013;88:130.

25 Pillar N, Yoffe L, Hod M, Shomron N: The possible involvement of microRNAs in preeclampsia and gestational diabetes mellitus. Best Pract Res Clin Obstet Gynaecol 2015;29:176-182. 


\section{Cellular Physiology \\ Cell Physiol Biochem 2016;39:1380-1390 \\ \begin{tabular}{l|l}
\hline DOI: $10.1159 / 000447842$ & (c) 2016 The Author(s). Published by S. Karger AG, Basel
\end{tabular} and Biochemistry Published online: September 08, 2016 www.karger.com/cpb}

Qian et al.: Expression Difference of Placental circRNAs in Preeclampsia

26 Morales-Prieto DM, Ospina-Prieto S, Schmidt A, Chaiwangyen W, Markert UR: Elsevier Trophoblast Research Award Lecture: origin, evolution and future of placenta miRNAs. Placenta 2014;35:S39-S45.

27 Jiang F, Li J, Wu G, Miao Z, Lu L, Ren G, Wang X: Upregulation of microRNA-335 and microRNA-584 contributes to the pathogenesis of severe preeclampsia through downregulation of endothelial nitric oxide synthase. Mol Med Rep 2015;12:5383-5390.

28 Ospina-Prieto S, Chaiwangyen W, Herrmann J, Groten T, Schleussner E, Markert UR, Morales-Prieto DM: MicroRNA-141 is upregulated in preeclamptic placentae and regulates trophoblast invasion and intercellular communication. Transl Res 2016;172:61-72.

29 Zhou X, Li Q Xu J, Zhang X, Zhang H, Xiang Y, Fang C, Wang T, Xia S, Zhang Q, Xing Q, He L, Wang L, Xu M, Zhao X: The aberrantly expressed miR-193b-3p contributes to preeclampsia through regulating transforming growth factor- $\beta$ signaling. Sci Rep 2016;6:19910. doi: 10.1038/srep19910.

30 Wang W, Feng L, Zhang H, Hachy S, Satohisa S, Laurent LC, Parast M, Zheng J, Chen DB. 2012: Preeclampsia up-regulates angiogenesis-associated MicroRNA (i.e., miR-17, -20a, and -20b) that target ephrin-B2 and EPHB4 in human placenta. J Clin Endocrinol Metab 2012;97:E1051-E1059.

31 Zhang YG, Yang HL, Long Y, Li WL: Circular RNA in blood corpuscles combined with plasma protein factor for early prediction of pre-eclampsia. BJOG 2016; doi:10.1111/1471-0528.13897 [Epub ahead of print].

32 Sankaralingam S, Arenas IA, Lalu MM, Davidge ST: Preeclampsia: current understanding of the molecular basis of vascular dysfunction. Expert Rev Mol Med 2006;8:1-20. 